\title{
Study of solid polymer electrolyte based on biodegradable polymer polycaprolactone
}

\author{
Evi Yulianti, Deswita, Sudaryanto, Mashadi* \\ Centre for Science and Technology of Advanced Materials - National Nuclear Energy Agency, Kawasan Puspiptek Serpong, Tangerang Selatan,
} Banten,Indonesia15314.

*Corresponding author: mashadi71@gmail.com,yulianti@batan.go.id

\section{Article history}

Received 7 June 2018

Revised 29 July 2018

Accepted 7 November 2018

Published Online 25 June 2019

\begin{abstract}
In this research, the polymer electrolyte material based on poly caprolactone (PCL) has been synthesized and characterized. Polycaprolactone is non-toxic and biodegradable polymer that is environmentally friendly. The preparation of the polymer electrolyte film was carried out by a casting method whereby the PCL polymer was dissolved in a tetrahydrofuran (THF) solvent. Lithium perchlorate salt $\left(\mathrm{LiClO}_{4}\right)$ as a source of lithium ions was added to solution with a composition (5-40)\% by weight. The solution was slowly evaporated in vacuum oven until the film was formed. The ionic conductivities, crystal structures, morphologies and thermal properties of polymer electrolytes were characterized by impedance spectroscopy, $x$-ray diffraction (XRD) and Fourier Transformation Infrared Spectrometer (FTIR), Scanning Electron Microscope (SEM) and Differential Scanning Calorimeter (DSC), respectively. The results of the conductivity measurements showed that the PCL conductivity increased from $3.45 \times 10^{-11} \mathrm{Scm}^{-1}$ to $5.52 \times 10^{-6} \mathrm{Scm}^{-1}$ with a $30 \%$ weight salt content of $\mathrm{LiClO}_{4}$. Observations with XRD showed a more amorphous polymer with more salt addition and FTIR results showed that there was interaction between active groups on polymers with salt. The thermal properties showed that the melting points of polymer became lower with more salt addition.
\end{abstract}

Keywords: Biodegradable polymer, polycaprolactone, polymer electrolyte, $\mathrm{LiClO}_{4}$

\section{INTRODUCTION}

Battery application as a practical energy source is increasing with the increasing use of portable electronic devices. Nowadays, most of power source systems are using lithium ion cell where in lithium battery, lithium ions tranfer from and into both electrodes. The lithium ion battery as secondary battery has many advantages such as high energy density, long life cycle and power density, making it as a promising candidate for automotive application. However, because of the safety issue of the devices, applications of the lithium batteries for electric vehicles are not being rapidly progressed. At present, the lithium battery that uses the liquid electrolyte may result some problems such as leakage and combustion due to production of gases upon overcharge or overdischarge process, as well as thermal runaway reaction when it is heated to high temperature [1][2].

The solid polymer electrolyte (SPE) is one of alternative substitutes for the liquid electrolyte in the electrochemical device. As the effort to create the new generation of rechargeable lithium batteries, the research for excellent solid polymer electrolyte with high ionic conductivity, good electrochemical stability and mechanical strength and large transport number is very important. Solid polymer electrolytes are essentially polymer salt complexes formed by dissolving salts in a polymer as matrix that contains a Lewis base which serves to coordinate the cations [3]. The solid polymer electrolytes have potential applications such as in lithium ion batteries, fuel cells, electrochromics, supercapacitors, solar cells, electrochemical display devices. The solid polymer electrolytes offer numerous advantages, such as improved safety, light weight, low cost, good mechanical properties, leakage proof and good thermal stability in combination with ease fabrication into desired shapes and sizes, as well as their capability to form electrode-electrolyte contact [4].

In the beginning, the synthetic polymer poly(ethylene oxide)(PEO) with various inorganic salts dissolved in its matrix is the most studied polymer by many researchers [5][6][7]. Nevertheless, the PEO has the high degree of crystallinity in the room temperature, that restricts its use in battery. PEO can be used only above temperature $60^{\circ} \mathrm{C}$. The development of solid electrolyte polymer materials continues to other types of synthetic polymers such as PMMA, PVDF and PVC [8][9][10][11]. However, synthetic polymers also have disadvantages such as high cost and hazardous material, and the environmental impact of the accumulation of technological garbage is also one of the problems that often arise, because the materials used are difficult to biodegrade by nature. The development of the new battery materials which are non-toxic, non-hazardous and environmental-friendly is very essential. Therefore, the application of biodegradable materials as polymer host in solid polymer electrolyte system can minimize the environmental problems because of its short biodegradable time and its eco-friendliness. A number of biodegradable polymers such as cellulose, starch, chitosan, and poly (vinyl alcohol) have been used as the host polymer for the preparation of solid or gel polymer electrolytes [12][13][14][15].

Polycaprolactone (PCL) is one of the most promising candidates as host of polymer electrolyte. PCL is a synthetic biodegradable polymer that is non toxic and has excellent level of biocompatibility, enabling it to be widely used in biomedical application. PCL contains carbonyl group as a Lewis base (ester oxygen) that can coordinate cations and 
also has low glass transition temperature $\left(-60^{\circ} \mathrm{C}\right)$ that allows polymer chain to exhibit segmental motion at room temperature, causing the ions to hop from one complexation site to another easily. Some researchers have attempted to make PCL as polymer electrolyte for supercapacitor application by complexing with various salts and as polymer host with other polymer-salt system [3][16][17].

In this work polycaprolactone as biodegradable polymer was made into an polymer electrolyte by complexing with lithium perchlorate $\left(\mathrm{LiClO}_{4}\right)$ salt with various compositions and the optimal composition was determined. This $\mathrm{PCL}_{-} \mathrm{LiClO}_{4}$ complex will replace conventional polymer electrolyte which is not environmental friendly.

\section{EXPERIMENTAL}

\section{Materials and methodology}

Polycaprolactone (PCL) with molecular weight 80.000 and $\mathrm{LiClO}_{4}$ (99.95\%) salt were purchased from Sigma Aldrich and used without any purification. Tetrahydrofuran (THF) (p.a) as PCL solvent was purchased from Merck.

Polymer electrolyte films based on polycaprolactone were prepared by dissolving polycaprolactone (PCL) in a tetrahydrofuran (THF) as solvent. After the PCL polymer was dissolved completely in the THF solvent, then the lithium perchlorate salts $\left(\mathrm{LiClO}_{4}\right)$ were added with varied composition (5-40)\% by weight. Mixture was stirred continuously for several hours with magnetic stirrer until all $\mathrm{LiClO}_{4}$ salts were completely dissolved. Then, the homogeneous solution was is poured into a petri dish and put into a vacuum oven and evaporated slowly for \pm 72 hours at $50^{\circ} \mathrm{C}$ until polymer electrolyte film (membrane) was formed. The films then were stored in a desiccators for 2 days to remove any traces solvent[1].

\section{Characterization}

Electrochemical impedance measurement was carried out in the frequency range of $42 \mathrm{~Hz}-5 \mathrm{MHz}$ with $\mathrm{AC}$ amplitude of $1.0 \mathrm{~V}$ using the HIOKI 3532-50 LCR hi-tester controlled by computer at room temperature. The polymer electrolyte samples were cut into small disks and clamped between the brass plate (SS) with the SS /electrolyte $\mathrm{SS} /$ polymer configuration.

Structural studies were analyzed by Empyrean PANalytical XRD $(45 \mathrm{kV}, 40 \mathrm{~mA})$ with monochromatic $\mathrm{Cu} \mathrm{K} \alpha$ radiation $(\lambda=0.15406$ $\mathrm{nm}$,) and scattering range angle $2 \theta=5-60^{\circ}$ with a step size 0.02 $\mathrm{deg} / \mathrm{step}$ at room temperature. The thermal properties of the electrolyte polymer were analyzed using Differential Scanning JADE DSC Perkin Elmer Calorimeter. The sample was heated on aluminum pan under the nitrogen atmosphere from room temperature to $120^{\circ} \mathrm{C}$ with a heating rate of $10^{\circ} \mathrm{C} / \mathrm{min}$. Surface morphology was observed with JSM-JSM6510LA Scanning Electron Microscope (SEM) by coating the surface of electrolytic polymer film with gold to prevent electrostatic charging. Fourier Transformation Infrared (FTIR) spectroscopy observation was conducted to study the interaction between polymer matrix and salt system. The spectrum was recorded using the Shimadzu Irprestige 21 Fourier transform infrared (FTIR) spectrometer with a transmission mode in the wavenumber range of $4000-500 \mathrm{~cm}^{-1}$.

\section{RESULTS AND DISCUSSION}

The electrochemical impedance spectroscopy (EIS) is widely used to characterize electrical properties of materials. Impedance parameters such as Z' ( $\left.Z_{\text {real }}\right)$ and Z' (Z $\left.Z_{\text {imaginary }}\right)$ were used to calculate DC conductivity $\left(\sigma_{\mathrm{dc}}\right)$, by using the following equation [4]:

$\sigma_{\mathrm{dc}}=\left(\begin{array}{c}1 \\ R b\end{array}\right) x\left(\begin{array}{l}d \\ A\end{array}\right)$

Where $d$ is the thickness of the polymer electrolyte film, $A$ is the electrode area and $R_{b}$ is the bulk resistance.

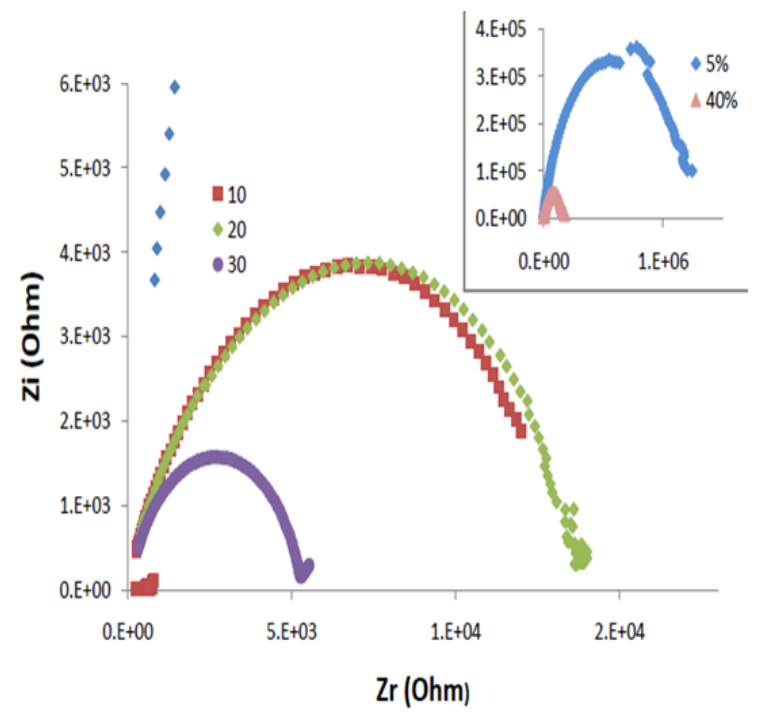

Fig. 1 Impedance spectra for $\mathrm{PCL} \mathrm{LiClO}_{4}$ complexes with different $\mathrm{LiClO}_{4}$ concentrations $(5,10,20,30,40)$ wt $\%$.

Fig. 1 shows the impedance plot of polymer electrolyte PCL$\mathrm{LiClO}_{4}$ with various compositions measured at room temperature. The impedance plot of polymer electrolyte has a typical shape of a semicircle arc in high-frequency regions and an inclined spike at low frequencies. This semi-circular shape is associated with the parallel combination of bulk resistance due to the migration of ions and with bulk capacitance due to the immobile polymer chains. Whereas the inclined spike represents the formation of double layer capacitors at the electrode-electrolyte interface. The inclination of the spike at an angle less than $90^{\circ}$ to the real axis indicates the inhomogeneous nature of the electrode-electrolyte interface. The bulk resistance $(R \mathrm{~b})$ of the polymer electrolyte film was obtained by the intercept of semicircle with the $x$ ( $Z_{\text {real }}$ axis. The electrical conductivity of the polymer electrolyte film was calculated by using Equation 1 [18].

From literature study, it is found that the pure PCL has the conductivity of $1.86 \times 10^{-11} \mathrm{Scm}-1$ at room temperature [3], while the pure PCL impedance plot was unseen at Fig.1 because its Rbulk was very high. It can be seen in Fig. 1 that the magnitude of bulk resistance was decreased with the increase of $\mathrm{LiClO}_{4}$ salt concentration. The conductivity of PCL-LICLO 4 complexes was increased with the increase of salt concentration and reached maximum value of $5.52 \times 10^{-}$ ${ }^{6} \mathrm{Scm}^{-1}$ for $30 \mathrm{wt} . \%$ salt addition, resulting in five orders higher than the value of conductivity of pure PCL as reported before. Further increment of the salt concentration (40 wt.\%) will decrease the ionic conductivity of PCL-LiCLO 4 polymer electrolyte. This is due to the ability of the PCL polymer to dissolve the salt is limited and the interaction between the PCL polymer and the lithium salt has saturated, causing the excess salt to re-crystallize and block the transport of ions within the polymer matrix.

The DC conductivity value of a solid electrolyte film can also be determined by conductivity measurement as a frequency function, as shown in Fig. 2. Fig. 2 presents the AC conductivity pattern that consisted of a frequency independent plateau in the low frequency region and exhibited dispersion at higher frequencies. In the plateau area, the conductivity was relatively constant and did not change with the increase of frequency. This plateau is the DC conductivity of the polymer electrolyte where the value was determined by extrapolating the plateau to the $y$-axis [19]. From the extrapolation result, it could be determined that the pure PCL conductivity value was $3.45 \times 10^{-11} \mathrm{Scm}^{-1}$, which is quite similar to the result obtained by previous researchers as mentioned above. 


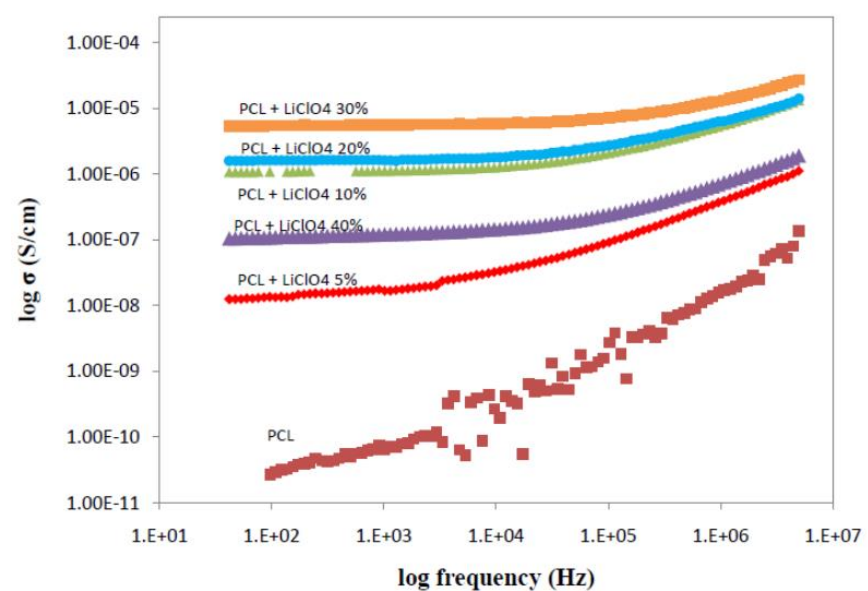

Fig. 2 AC conductivity spectra for $\mathrm{PCL} / \mathrm{LiClO}_{4}$ complexes at various concentrations of $\mathrm{LiClO}_{4}(5,10,20,30,40)$ wt\%

The diffraction peak at an angle of $32^{\circ}$ was lower while the diffraction peak at an angle of $35^{\circ}$ was increased with the increase in the value of $x$, and even disappeared in the sample with the composition of the value $\mathrm{x}=1.0$. The diffraction pattern for $\mathrm{x}=1.0$ wasis seen only one major peak ie the diffraction angle $2 \theta$ around the $35^{\circ}$ angle, which is the top of the field 311 of $\mathrm{ZnFe}_{2} \mathrm{O}_{4}$ indicating the formation of a single phase with a ferrite spinel structure having a cubic crystal structure with space group Fd3m with lattice parameter of $\mathrm{a}=\mathrm{b}$ $=\mathrm{c}=0,58836 \mathrm{~nm}$ at room temperature.

Overall, the conductivity value of PCL electrolyte polymer with various of $\mathrm{LiClO}_{4}$ salt concentrations was is tabulated in Table 1:

Table 1 DC Conductivity of PCL-LiClO

\begin{tabular}{cccc}
\hline No & $\begin{array}{c}\mathrm{LiClO}_{4} \\
(\mathbf{w t} . \%)\end{array}$ & $\begin{array}{c}\mathbf{R}_{\mathbf{b}} \\
(\mathbf{O h m})\end{array}$ & $\begin{array}{c}\text { Conductivity } \\
\left(\mathbf{S c m}^{-1}\right)\end{array}$ \\
\hline 1 & 0 & $6.36 \times 10^{8}$ & $3.4450 \times 10^{-11}$ \\
2 & 5 & $1.37 \times 10^{6}$ & $1.4541 \times 10^{-8}$ \\
3 & 10 & $1.37 \times 10^{4}$ & $1.0564 \times 10^{-6}$ \\
4 & 20 & $1.42 \times 10^{4}$ & $1.5516 \times 10^{-6}$ \\
5 & 30 & $5.31 \times 10^{3}$ & $5.5240 \times 10^{-6}$ \\
6 & 40 & $1.89 \times 10^{5}$ & $1.1326 \times 10^{-7}$ \\
\hline
\end{tabular}

The XRD patterns of PCL-LiClO 4 complexes polymer electrolyte with various compositions of $\mathrm{LiClO}_{4}$ measured at room temperature were shown in Fig. 3. For pure PCL, there were three sharp diffraction peaks at $2 \theta=21.2,22.1$ and 23.79 angles, which are planes of (110), (111), and (200) of the orthorhombic crystal system, respectively. These sharp peaks are characteristics of the crystalline phase of PCL, which originated from the ordering of polymer side chains due to the intermolecular interaction between PCL chains through the hydrogen bonding. In addition to these crystalline peaks, a small continuous spectrum centered on $2 \theta=21.0^{\circ}$ was observed, showing that the film is semicrystalline, comprising both crystalline and amorphous phases. The peak position is not different from the XRD measurements by previous researchers [16][20].

The addition of the $\mathrm{LiClO}_{4}$ salt to the polymer matrix changes the PCL X ray diffraction pattern. The addition of $5 \mathrm{wt} . \%$ salt has not changed the PCL diffraction pattern significantly. The addition of $10 \%$ $\mathrm{LiCLO}_{4}$ salt resulted in the diffraction peaks intensity to decrease and the diffraction peaks to become broader. This indicates that there is phase transformation from crystalline into an amorphous phase due to the formation of lithium and polymeric salt complexes. The more the amorphous phase is formed, the higher the conductivity of the electrolyte polymer will increase. The result inferred from XRD study is in good agreement with conductivity measurements as described previously.

The addition of 20 and $30 \mathrm{wt} \%$ lithium salt made the peak became broader and at the $2 \theta \geq 30^{\circ}$ angle, there were other peaks appeared, indicating the existence of another phase in the electrolyte polymer system. When the lines were drawn along the angles downward, it was found that characteristic peak of $\mathrm{LiClO} 4$ salt was observed, proving that it does not dissociate completely in the polymer matrix and does not form complex with PCL polymer. In otherwise, the addition of $40 \mathrm{wt} . \%$ lithium salt made the diffraction peak became sharpen, indicating that the crystalline phase of PCL is increased, resulting in the conductivity of the polymer electrolyte to decrease. This is due to the more unsolved salt in the polymer matrix.

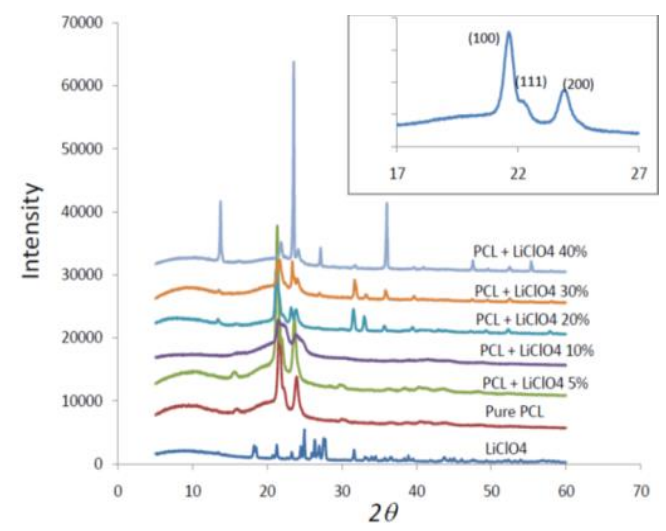

Fig. 3 XRD patterns of $\mathrm{PCL}-\mathrm{LiClO}_{4}$ complexes at different compositions of $\mathrm{LiClO}_{4}$. Insert is the expanded XRD showing crystalline orientation of PCL.

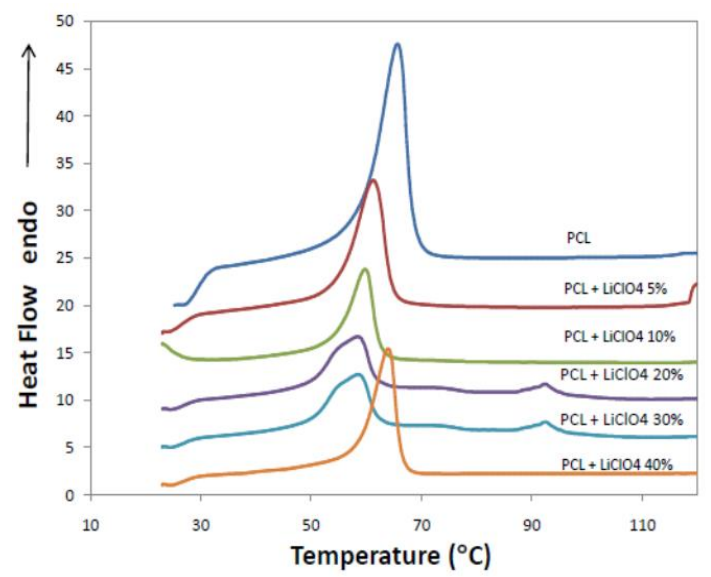

Fig. 4. DSC thermogram of $\mathrm{PCL}-\mathrm{LiClO}_{4}$ with different compositions.

Fig. 4 shows the DSC thermogram of complex polymer PCL-LiClO with different compositions in wt.\%. Pure PCL has sharp endothermic melting point at $63.97^{\circ} \mathrm{C}$, this value is different with the previous work done by [16] that made complex PCL with ZnTr. Phase transition temperature of pure PCL showed at $-59.8^{\circ} \mathrm{C}$, which is recognized to the glass transition temperature $(\mathrm{Tg})[20]$, but in this work, it was not measured because of the instrument limitation. Addition of lithium salt to the polymer matrix has changed the degree of crystallinity of film. The addition of $5 \%$ wt of $\mathrm{LiClO}_{4}$ to PCL matrix resulted the melting point to shift to lower temperature at $62.49^{\circ} \mathrm{C}$ and the endothermic peak became broader, meaning that the crystallinity degree becomes lower because there is interaction between polymer matrix and lithium salt. The more salt addition to polymer, the lower melting temperature of polymer electrolyte and it reaches the lowest temperature at $60.70^{\circ} \mathrm{C}$ with $30 \mathrm{wt} \%$ lithium salt addition. There were multiple endothermic peaks appeared at Fig. 4 for $20 \%$ and $30 \%$ salt addition at temperature up to $90^{\circ} \mathrm{C}$. Those multiple melting peaks occurred because of recrystallization process during melting or electrolyte aggregation of polymer segments of different chain lengths. These multiple peaks also appeared at the work by Woo [20] and Barbosa [21]. The addition of $40 \mathrm{wt} . \%$ salt made the melting point of polymer electrolyte to increase. The interaction between polymer and lithium salt is saturated and the salt is recrystallized. This tendency is consistent with XRD pattern aforementioned above. 
The melting enthalpy of the polymer electrolyte samples $\Delta \mathrm{H}$ was the area under the melting peaks and it was then used to calculate the degree of crystallinity of polymer $(\chi)$ using the following equation :

$\chi=\frac{\Delta H m}{\Delta H m o} \times 100 \%$

Where $\Delta \mathrm{Hm}$ is the melting enthalpy of complexes PCL and lithium salt and $\Delta \mathrm{Hm}^{\circ}$ is melting enthalpy of pure PCL. The melting point, the enthalpy of melting and degree of crytallization of complexes PCL$\mathrm{LiClO}_{4}$ were presented in Table 2. $\Delta \mathrm{Hm}$ of complexes PCL-LiClO 4 was found to decrease when the salt content was increased. The salt addition also reduced the relative degree of crystallinity $\left(\chi_{c}\right)$ from $100 \%$ to $34.56 \%$ after $30 \mathrm{wt} . \%$ lithium salt incorporation, and increased again with $40 \mathrm{wt} . \%$ salt addition. This trend is appropriate with the XRD data.

Table 2 The melting point, the enthalpy of melting and degree of crystallization of complexes PCL- $\mathrm{LiClO}_{4}$.

\begin{tabular}{|c|c|c|c|}
\hline Sample & $\operatorname{Tm}\left({ }^{\circ} \mathrm{C}\right)$ & $\Delta \mathrm{Hm}(\mathrm{J} / \mathrm{g})$ & $\chi_{c}(\%)$ \\
\hline PCL & 63.97 & 152.23 & 100 \\
\hline $\begin{array}{l}\mathrm{PCL}+\mathrm{LiClO}_{4} 5 \% \\
\mathrm{PCL}+\mathrm{LiClO}_{4} 10 \% \\
\mathrm{PCL}+\mathrm{LiClO}_{4} 20 \% \\
\mathrm{PCL}+\mathrm{LiClO}_{4} 30 \% \\
\mathrm{PCL}+\mathrm{LiClO}_{4} 40 \%\end{array}$ & $\begin{array}{l}62.49 \\
61.26 \\
59.74 \\
60.70 \\
58.50\end{array}$ & $\begin{array}{l}101.87 \\
71.41 \\
58.31 \\
52.61 \\
97.74\end{array}$ & $\begin{array}{l}66.72 \\
46.91 \\
38.30 \\
34.56 \\
64.21\end{array}$ \\
\hline
\end{tabular}

The surface morphology of selected samples was analyzed using Scanning Electron Microscope (SEM) and observations were carried out with a magnification of 500x. Figure 5a-c display the SEM images of PCL-LiClO 4 complexes for $0,5,20$ wt.\% lithium salt content. In Fig.5 a, pure PCL exhibited the spherulite texture with individual spherulite diameter in several hundreds of micrometer. Spherulites arise via sporadic nucleation and grow radially until they force each other at straight boundaries [16][22]. The surface of PCL film was relatively coarse with spherulites packed closely with each other. With the lithium salt addition, the spherulites size was decreased significantly and the number of spherulites was increased (Fig. 5b). The increasing of salt content makes the surface of electrolyte film becomes smoother because of the appearance of amorphous phase. Fig. 5c shows surface morphology PCL- $\mathrm{LiClO}_{4}$ complex for $20 \%$ salt. There were two phases on the film morphology ie the spherulite at the bottom and the recrystallized lithium salt on the surface which fine threadshaped. The appearance of salt crystal means that PCL polymers have limited ability to solve or interact with the lithium salt.

To confirm the interaction or the complexation between the dopant salt and the polymer matrix, FTIR spectroscopy was used in this work. The FTIR spectra of PCL-LiClO 4 complexes with various salt contents in wt.\% were presented in Figure 6. Spectrum of pure PCL was shown in Fig.6A, has the absorption peak at region $1800-1650 \mathrm{~cm}^{-1}$ of the carbonyl $(\mathrm{C}=\mathrm{O})$ group. Other characteristic peaks of pure PCL were observed at 1182,1243,1290, 1182 and $964 \mathrm{~cm}^{-1}$, corresponding to symmetric and asymmetric COC stretching, $\mathrm{C}-\mathrm{O}$ and $\mathrm{C}-\mathrm{C}$ stretching in crystalline and amorphous phases, $\mathrm{OC}-\mathrm{O}$ stretching and $\mathrm{CH}_{2}$ rocking, respectively [16].

The carbonyl group of PCL is strong Lewis base and highly sensitive to ionic interactions. The lithium ion tends to make complex with oxygen atom of carbonyl group. The salt addition to PCL polymer makes the $\mathrm{C}=\mathrm{O}$ stretching band broader and a peak shoulder appears at around $1650 \mathrm{~cm}^{-1}$. The increase of $\mathrm{LiClO}_{4}$ content makes the shoulder peak to be broadened gradually corresponding to more $\mathrm{Li}^{+}$ion interaction with the polymer. The peak intensity $\mathrm{C}=\mathrm{O}$ band at around $1750 \mathrm{~cm}^{-1}$ becomes lower, corresponding to less free $\mathrm{C}=\mathrm{O}$ bonding in this polymer electrolyte system [23].

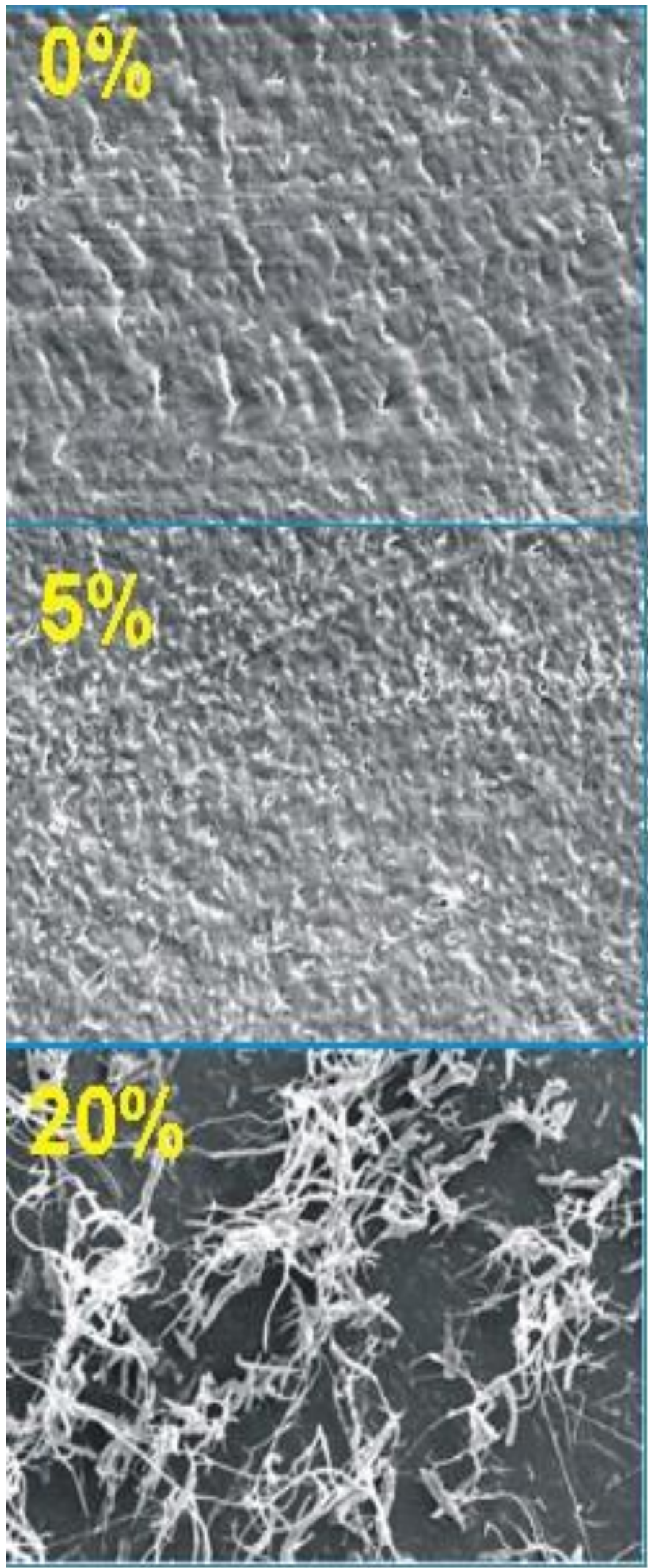

Fig. 5 Morphology of PCL-LiClO 4 complexes in 0\%, 5\% and 20\% wt.\% $\mathrm{LiClO}_{4}$. 


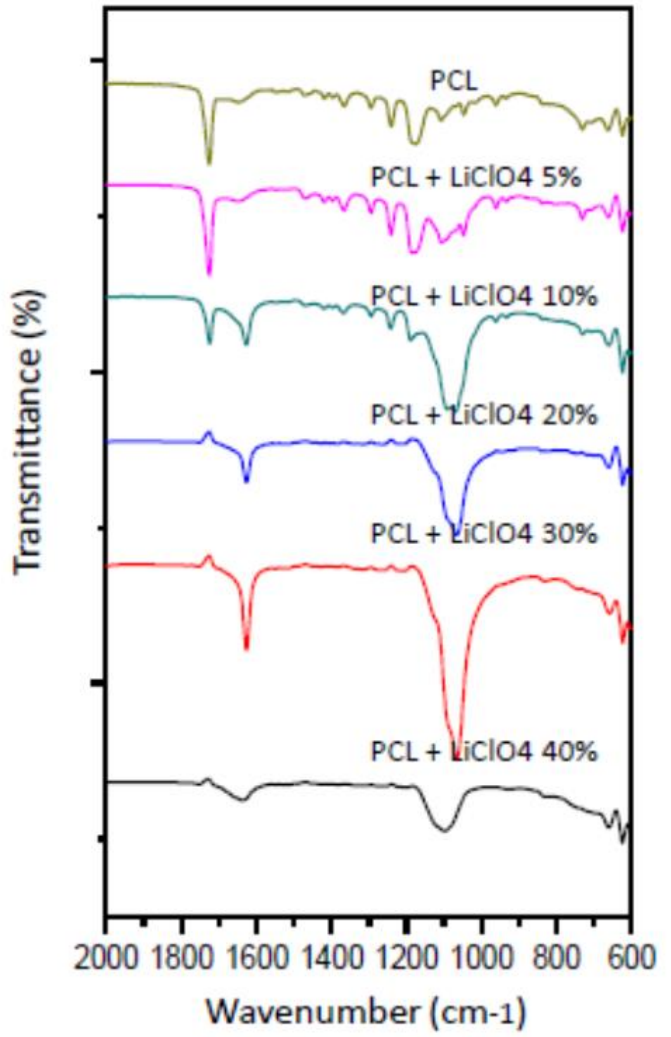

Fig. 6 FTIR spectra PCL-LiClO 4 complexes with various compositions.

The absorption peak around $1100 \mathrm{~cm}^{-1}$ (Fig.6) was characteristic of $\mathrm{LiClO}_{4}$ and this peak was shifted to $1071 \mathrm{~cm}^{-1}, 1068 \mathrm{~cm}^{-1}$ and $1054 \mathrm{~cm}$ ${ }^{1}$ for 10,20 , and $30 \mathrm{wt} . \% \mathrm{LiClO}_{4}$ added to polymer matrix respectively, which their intensities were increased corresponding to interaction of assymetrical stretching vibration of $\mathrm{ClO}_{4}^{-}$ion appeared at $1100 \mathrm{~cm}^{-1}$. This tendency is quite similar with previous work by S.Abarna et.al and Selvasekarapandian who made polymer electrolyte based on polyethylene glycol/LiClO 4 and $\mathrm{PVAc} / \mathrm{LiClO}_{4}$, respectively [24][25]

\section{CONCLUSION}

Polymer electrolytes film based on biodegradable polymer polycaprolactone (PCL) has been successfully prepared by casting method. The addition of the $\mathrm{LiClO}_{4}$ salt succeeded in increasing the ionic conductivity of the PCL polymer from $2.45 \times 10^{-11} \mathrm{Scm}^{-1}$ to 5.52 $\times 10^{-6} \mathrm{Scm}^{-1}$ with 30 wt. $\% \mathrm{LiClO}_{4}$ salt addition. The addition of the $\mathrm{LiClO}_{4}$ salt also affected the intrinsic properties of the PCL polymer in which the crystallinity was decreased, as well as the melting point of the polymer. FTIR spectra showed that there were interactions between polymer hosts with lithium salt to make PCL- $\mathrm{LiClO}_{4}$ complexes.

\section{ACKNOWLEDGEMENT}

This research was financially supported by the Center for Science and Technology of Advanced Materials, National Nuclear Agency (BATAN) Indonesia, DIPA 2016 Grant No. 3446.245.001.

\section{REFERENCES}

[1] C. P. Fonseca, F. Cavalcante, F. A. Amaral, C. A. Zani Souza, S. Neves. Thermal and conduction properties of a PCL-biodegradable gel polymer electrolyte with $\mathrm{LiClO}_{4}, \mathrm{LiF}_{3}, \mathrm{CSO}_{3}, \mathrm{LiBF}_{4}$ salts. International Journal of Electrochemical Science, vol. 2, pp. 52 - 63, 2007.

[2] E. Kartini, W. Honggowiranto, H. Jodi, A. K. Jahya. Synthesis and characterization of new solid electrolyte layer $\left(\mathrm{Li}_{2} \mathrm{O}\right)_{2}\left(\mathrm{P}_{2} \mathrm{O}_{5}\right)_{\mathrm{Y}}$. 14th Asian Conference on Solid State Ionics, vol. 2, pp. 978 - 981, 2014.

[3] H. J. Woo, C.-W. Liew, S. R. Majid, a. K. Arof. Poly( -caprolactone)based polymer electrolyte for electrical double-layer capacitors. High Performance Polymers, vol. 26, no. 6, pp. 637 - 640, 2014.
[4] S. Aziz. Li+ ion conduction mechanism in poly ( $\varepsilon$-caprolactone)-based polymer electrolyte. Iranian Polymer Journal, vol. 22, no. 12, pp. 877 883, 2013.

[5] E. Quartarone, P. Mustarelli, A. Magistris. PEO-based composite polymer electrolytes, vol. 110, no. February, pp. 1-14, 1998.

[6] W. Li, Y. Pang, J. Liu, G. Liu, Y. Wang, Y. Xia. RSC Advances, vol. 7, pp. 23494-23501, 2017.

[7] J. Zhang, N. Zhao, M. Zhang, Y. Li, P. K. Chu, X. Guo, Z. Di, X. Wang, and H. Li. Nano energy flexible and ion-conducting membrane electrolytes for solid-state lithium batteries: Dispersion of garnet nanoparticles in insulating polyethylene oxide. Nano Energy, vol. 28, pp. 447-454, 2016.

[8] C. Kuo, W. Li, P. Chen, J. Liao, C. Tseng, T. Wu. Effect of plasticizer and lithium salt concentration in PMMA- based composite polymer electrolytes. International Journal of Electrochemical Science, vol. 8, pp. 5007-5021, 2013.

[9] M. M. Noor, M. A. Careem, S. R. Majid, A. K. Arof. Characterisation of plasticised PVDF-HFP polymer electrolytes. Materials Research Innovations, vol. 15, no. s2, pp. s157-s160, 2011.

[10] M. Y. A. Rahman, A. Ahmad, T. K. Lee, Y. Farina, H. M. Dahlan. Effect of ethylene carbonate (EC) plasticizer on poly (vinyl chloride)-liquid $50 \%$ epoxidised natural rubber (lenr50) based polymer electrolyte. Materials Sciences and Applications, vol. 2, no. July, pp. 818-826, 2011.

[11] S. K. Deraman, N. S. Mohamed, R. H. Y. Subban. Conductivity and electrochemical studies on polymer electrolytes based on poly vinyl (chloride) - ammonium triflate-ionic liquid for proton battery. International Journal of Electrochemical Science, vol. 8, no. 1, pp. 1459 $-1468,2013$.

[12] N. H. Ahmad, M. I. N. Isa. Ionic conductivity and electrical properties of carboxymethyl cellulose - nh $4 \mathrm{cl}$ solid polymer electrolytes. Journal of Engineering Science and Technology, vol. 11, no. 6, pp. 839-847, 2016.

[13] M. H. Khanmirzaei, S. Ramesh. Ionic transport and FTIR properties of lithium iodide doped biodegradable rice starch based polymer electrolytes. International Journal of Electrochemical Science, vol. 8, pp. 9977-9991, 2013.

[14] E. Yulianti, A. K. Karo, L. Susita. Synthesis of electrolyte polymer based on natural polymer chitosan by ion implantation technique. Procedia Chemistry, vol. 4, pp. 202-207, 2012.

[15] S. Çavuş and E. Durgun. Poly (vinyl alcohol) based polymer gel electrolytes: Investigation on their conductivity and characterization. Acta Physica Polonica A, vol. 129, no. 4, pp. 621-624, 2016.

[16] K. Sownthari. Synthesis and characterization of an electrolyte system based on a biodegradable polymer. Express Polymer Letters, vol. 7, no. 6, pp. 495-504, 2013.

[17] H. J. Woo and A. K. Arof. Vibrational studies of flexible solid polymer electrolyte based on PCL-EC incorporated with proton conducting NH4SCN. Spectrochimica Acta Part A, vol. 161, no. March, pp. 44-51, 2016.

[18] S. Subramanian and V. Pandi. Preparation and characterization of PVA complexed with amino acid, proline. Ionics International Journal of Ionics The Science and Technology of Ionic Motion. Berlin: Springer, 2014.

[19] M. Prabu, S. Selvasekarapandian, A. R. Kulkarni, G. Hirankumar, C. Sanjeeviraja. Conductivity and dielectric studies on $\mathrm{LiCeO}_{2}$. Journal of Rare Earths, vol. 28, no. 3, pp. 435-438, 2010.

[20] H. J. Woo, S. R. Majid, and A. K. Arof. Effect of ethylene carbonate on proton conducting polymer electrolyte based on poly(??-caprolactone) (PCL). Solid State Ionics, vol. 252, pp. 102-108, 2013.

[21] P. C. Barbosa, L. C. Rodrigues, M. M. Silva, and M. J. Smith. Characterization of pTMC n LiPF 6 solid polymer electrolytes. Solid State Ionics, vol. 193, pp. 39-42, 2011.

[22] M. Ravi, S. Song, and J. Wang. Preparation and characterization of biodegradable poly ( $\varepsilon$-caprolactone)-based gel polymer electrolyte films. International Journal of Ionics The Science and Technology of Ionic Motion, Vol. 22, No. 5. pp. 661-670, 2016.

[23] I. Wu, F. Chang. Determination of the interaction within polyester-based solid polymer electrolyte using FTIR spectroscopy. Polymer, vol. 48, issue 4, 989-996, 2007.

[24] S. Abarna and G. Hirankumar. Study on new lithium ion conducting electrolyte based on Polyethylene glycol-p-tertoctyl phenyl ether and lithium perchlorate. International Journal of ChemTech Research, vol. 6 , no. 13, pp. 5161-5167, 2014.

[25] S. Selvasekarapandian, R. Baskaran, and O. Kamishima, "Laser Raman and FTIR studies on $\mathrm{Li}+$ interaction in PVAc - $\mathrm{LiClO} 4$ polymer electrolytes. Spectrochimica Acta Part A Molecular and Biomolecular Spectroscopy, vol. 65(5), pp. 1234-1240, 2006. 